\title{
Muscle involvement in limb-girdle muscular dystrophy with GMPPB deficiency (LGMD2T)
}

\section{OPEN}

S.T. Oestergaard, BSc T. Stojkovic, PhD J.R. Dahlqvist, MD

C. Bouchet-Seraphin, $\mathrm{PhD}$

J. Nectoux, PhD

F. Leturcq, PharmD

M. Cossée, PhD

G. Solé, MD

C. Thomsen, DMSc

T.O. Krag, PhD

J. Vissing, DMSc

Correspondence to

Sofie T. Oestergaard: sofie.thuroe.oestergaard.02

$@$ regionh.dk
Supplemental data at Neurology.org/ng

\section{ABSTRACT}

Objective: In this study, muscle involvement assessed by MRI and levels of GMPPB and glycosylation of $\alpha$-dystroglycan expression in muscle were examined in patients with limb-girdle muscular dystrophy (LGMD) type 2T.

Methods: Six new patients with genetically verified mutations in GMPPB were studied. T1weighted magnetic resonance images were obtained in 4 participants. Muscle strength and potential involvement of extramuscular organs were examined. Glycosylation of $\alpha$-dystroglycan in muscle was studied, and GMPPB and $\alpha$-dystroglycan expression was analyzed by Western blotting. Prevalence of LGMD2T was calculated from the total LGMD population in Denmark. GMPPB was sequenced in all unclassified cases.

Results: Two patients carried 3 new mutations in GMPPB. The other 4 patients carried previously described pathogenic mutations in GMPPB. MRI showed that the paraspinal muscles were the most affected, followed by involvement of hamstrings. Our results showed a loss of glycosylation of $\alpha$-dystroglycan as well as secondary loss of merosin expression on Western blotting. The prevalence of LGMD2T in the Danish cohort of patients with LGMD is 1.5\%.

Conclusions: The new findings of this study are (1) the consistent finding of a preferential affection of paraspinal and hamstring muscles in LGMD2T, (2) 3 new mutations in GMPPB, (3) variable loss of glycosylation tested with IIH6 and VIA4 antibodies, and (4) a prevalence of LGMD2T of 1.5\% in a well-characterized Danish LGMD cohort. Neurol Genet 2016;2:e112; doi: 10.1212/NXG.0000000000000112

\section{GLOSSARY}

CK = creatine kinase; $\mathbf{C M D}=$ congenital muscular dystrophy; GDP = guanosine diphosphate; LGMD = limb-girdle muscular dystrophy.

Limb-girdle muscular dystrophy (LGMD) designates a heterogeneous group of more than 31 muscle disorders characterized by weakness and atrophy of the proximal muscles of the shoulder and pelvic girdles.

Recently, a new gene $(G M P P B)$, responsible for causing both LGMD type $2 \mathrm{~T}$ and congenital muscular dystrophy (CMD), was identified. ${ }^{2} G M P P B$ codes for the protein, guanosine diphosphate (GDP)-mannose pyrophosphorylase B (GMPPB), which catalyzes the formation of GDP-mannose, required for glycosylation of proteins and lipids, including $\alpha$-dystroglycan. $\alpha$-dystroglycan is part of the dystroglycan protein complex, which forms a critical link between the contractile elements and extracellular matrix in muscle cells. It is important for cell stability and membrane integrity. ${ }^{3}$

Mutations in GMPPB lead to hypoglycosylation of $\alpha$-dystroglycan. ${ }^{2}$ Approximately 40 patients with $G M P P B$ mutations and muscular dystrophy have been reported worldwide

From the Copenhagen Neuromuscular Center (S.T.O., J.R.D., T.O.K., J.V.), Department of Neurology, Department of Diagnostic Radiology (C.T.), Rigshospitalet, University of Copenhagen, Denmark; AP-HP, Institute of Myology (T.S.), Centre de reference des maladies neuromusculaires Paris Est, G-H Pitié-Salpêtrière; AP-HP, Hôpital Bichat (C.B.-S.), Département de Biochimie et de Génétique, Paris; Service de génétique et biologie moléculaires (J.N., F.L.), HUPC Hôpital Cochin, Paris; Laboratoire de Génétique Moléculaire and UE 7402 (M.C.), CHRU Montpellier, Université Montpellier; and Center of Reference for Neuromuscular Disorders (G.S.), CHU Bordeaux, France.

Funding information and disclosures are provided at the end of the article. Go to Neurology.org/ng for full disclosure forms. The Article Processing Charge was paid by the authors.

This is an open access article distributed under the terms of the Creative Commons Attribution-NonCommercial-NoDerivatives License 4.0 (CC BY-NC-ND), which permits downloading and sharing the work provided it is properly cited. The work cannot be changed in any way or used commercially. 
with phenotypes equally distributed between LGMD and CMD. ${ }^{2}$ The majority of the patients with the LGMD phenotype are able to walk short distances. Patients with GMPPB deficiency and CMD have been described with hypotonia, epilepsy, intellectual disability, cataracts, cardiomyopathy, cerebellar/ pontine hypoplasia, and neuromuscular junction dysfunction. ${ }^{4-6}$ However, phenotypic characterization in patients with the LGMD phenotype, especially knowledge about the pattern of muscle involvement, is lacking. We therefore studied 6 new cases of LGMD2T clinically, by MRI, with immunohistology and Western blotting, and estimated the prevalence of LGMD2T among LGMDs in Denmark.

METHODS Standard protocol approvals, registrations, and patient consents. The study was approved by the Danish National Committee on Health Research Ethics (H-3-2012-163 with amendment \#41665, \#43449, and \#50556). All patients consented to participate.
Participants. Six patients from nonconsanguineous parents and with genetically verified LGMD2T were included. For demographic data, see table. Two of them (cases 1 and 5) were brothers.

Clinical evaluation. Standard clinical and laboratory assessments are evident from the table. Limb muscle strength was assessed by manual muscle testing (Medical Research Council scale).

MRI. The MRI protocol included T1-weighted brain and wholebody examination. Four cross-sectional slices were chosen for the evaluation of muscle involvement (figure 1). Replacement of muscle by fat was scored using the Mercuri scale?

Muscle biopsy and molecular examinations. Muscle biopsies were procured from the tibialis anterior or deltoid muscles and were analyzed immunohistochemically for glycosylated $\alpha$-dystroglycan and merosin and by Western blotting for GMPPB and $\alpha$-dystroglycan, using standard protocols. ${ }^{8}$

The Copenhagen Neuromuscular Center is a national referral center for people affected by muscle diseases, and 201 patients are registered with LGMD, including 23 unclassified cases. The 23 unclassified Danish patients and the 3 French and 3 Danish patients reported with LGMD2T were tested for aberrations in GMPPB using exome sequencing technology. A prevalence of LGMD2T in the Danish LGMD cohort was calculated as follows: number of Danish LGMD2T patients/total number of patients with LGMD in the cohort.

\begin{tabular}{|c|c|c|c|c|c|c|}
\hline \multirow[t]{2}{*}{ Table } & characteristic & f 6 patients wi & ID2T & & & \\
\hline & Case 1 & Case 2 & Case 3 & Case 4 & Case $5^{a}$ & Case 6 \\
\hline Mutation & $\begin{array}{l}\text { c.859C }>\text { T } \\
\text { (p.Arg287Trp), } \\
\text { c.79G }>\text { C } \\
\text { (p.Asp27His) }\end{array}$ & $\begin{array}{l}\text { c.859C }>T \\
\text { (p.Arg287Trp), } \\
\text { c.79G }>C \\
\text { (p.Asp27His) }\end{array}$ & $\begin{array}{l}\text { c.464G }>\text { A } \\
\text { (p.Arg155His), } \\
\text { c.10391043dup } \\
\text { (p.lle349Serfs })\end{array}$ & $\begin{array}{l}\text { c.79G }>C \\
\text { (p.Asp27His), } \\
\text { c.760G }>\text { A } \\
\text { (p.Val254Met) }\end{array}$ & $\begin{array}{l}\text { c.859C }>T \\
\text { (p.Arg287Trp), } \\
\text { c.79G }>C \\
\text { (p.Asp27His) }\end{array}$ & $\begin{array}{l}\text { c. } 902 C>G \\
\text { (p.Ser301Cys), } \\
\text { c.1069G>A } \\
\text { (p.Val357lle) }\end{array}$ \\
\hline Sex/age, y & Male/51 & Female/44 & Female/32 & Female/33 & Male/53 & Male/59 \\
\hline Disease onset, $y$ & 15 & 30 & 12 & 18 & 5 & 25 \\
\hline $\begin{array}{l}\text { Presenting } \\
\text { symptoms }\end{array}$ & $\begin{array}{l}\text { Difficulties } \\
\text { running }\end{array}$ & $\begin{array}{l}\text { Difficulties } \\
\text { climbing stairs }\end{array}$ & $\begin{array}{l}\text { Difficulties } \\
\text { running }\end{array}$ & $\begin{array}{l}\text { Exercise intolerance } \\
\text { with fatigue }\end{array}$ & $\begin{array}{l}\text { Walked at } \\
5 \text { years old }\end{array}$ & $\begin{array}{l}\text { Difficulties walking } \\
\text { and running }\end{array}$ \\
\hline Age at MRI, y & 51 & 44 & 27 & 28 & ND & ND \\
\hline Origin & CA, DK & CA, DK & $\mathrm{CA}, \mathrm{Fr}$ & $\mathrm{CA}, \mathrm{Fr}$ & CA, DK & $\mathrm{CA}, \mathrm{Fr}$ \\
\hline MMSE & $30 / 30$ & $30 / 30$ & $30 / 30$ & $27 / 30$ & ND & $28 / 30$ \\
\hline FVC, \% & 59 & 66 & 76 & 95 & 61 & 43 \\
\hline ECG & Normal & Normal & Normal & Normal & Normal & Normal \\
\hline Cardiac echo & Normal & Normal & Normal & Normal & Normal & Ejection fraction $48 \%$ \\
\hline $10-\mathrm{m}$ walk test, s & 13 & 11 & 6 & 14 & 7 & Cannot walk \\
\hline Walking aids & $\begin{array}{l}\text { Wheelchair, but } \\
\text { ambulant }\end{array}$ & Scooter & None & $\begin{array}{l}\text { Wheelchair, but } \\
\text { ambulant }\end{array}$ & None & Wheelchair \\
\hline FSS & $48 / 63$ & $61 / 63$ & $35 / 63$ & $58 / 63$ & ND & $43 / 63$ \\
\hline EMG & Myopathic & ND & Myopathic & Myopathic & ND & ND \\
\hline Decrement, ${ }^{b} \%$ & $26-29$ & ND & $11-13$ & $10-23$ & ND & 13 \\
\hline CK, U/L & 2,390 & 1,520 & 1,604 & 1,200 & 1,327 & 619 \\
\hline
\end{tabular}

Abbreviations: $\mathrm{CK}=$ creatine kinase; $\mathrm{CA}=$ Caucasian; DK = Danish; Fr $=$ French; FSS = Fatigue Severity Scale; FVC = forced vital capacity; MMSE $=$ Mini-Mental State Examination; ND = not done.

${ }^{a}$ Data obtained at the latest visit 12 years ago, at age 41 years. This patient is the brother of case 1 and has intellectual disability due to prolonged oxygen deficiency at birth and could not cooperate to perform MRI.

${ }^{b}$ Analyses of decrement, using 3-Hz stimulation frequency, were obtained in different muscles (recording electrode on trapezius muscle, anconeus muscle, and the tibialis anterior muscle, respectively). 

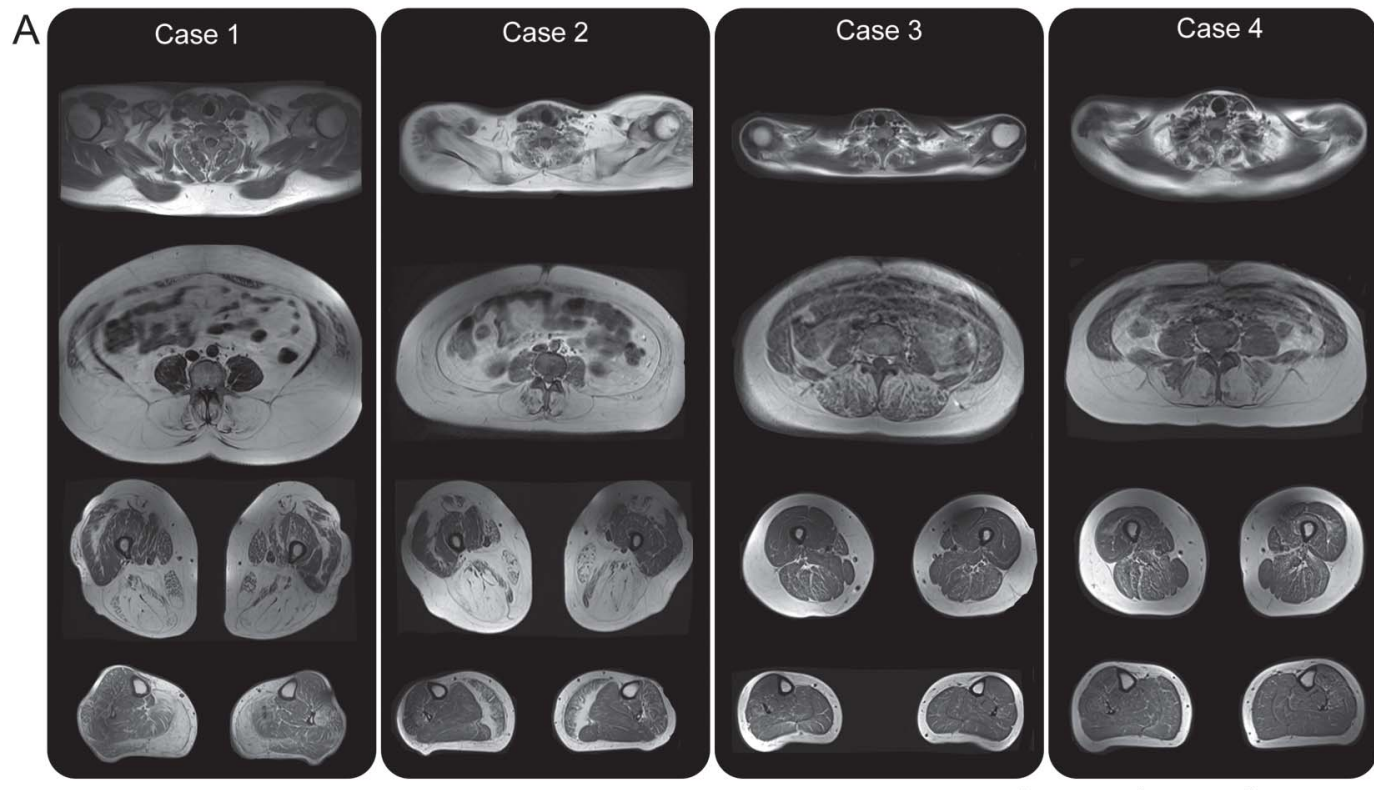

B

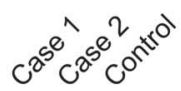

GMPPB - $\alpha$-tubulin

C
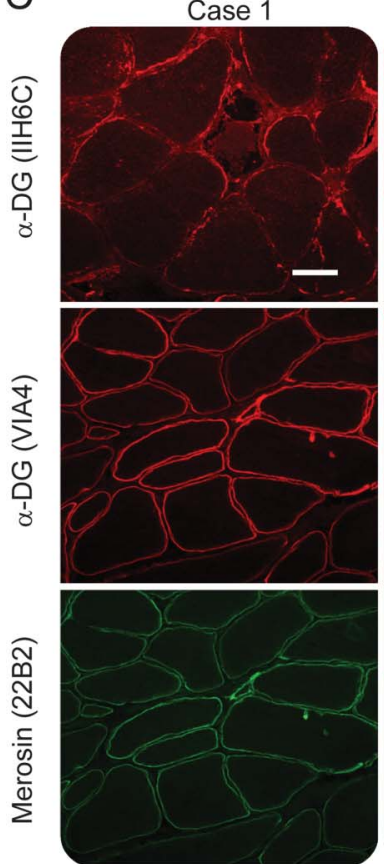

Case 2
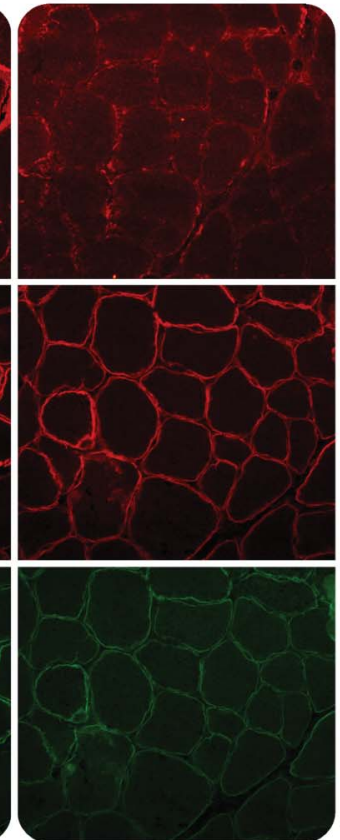

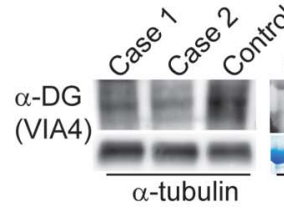

Case 5
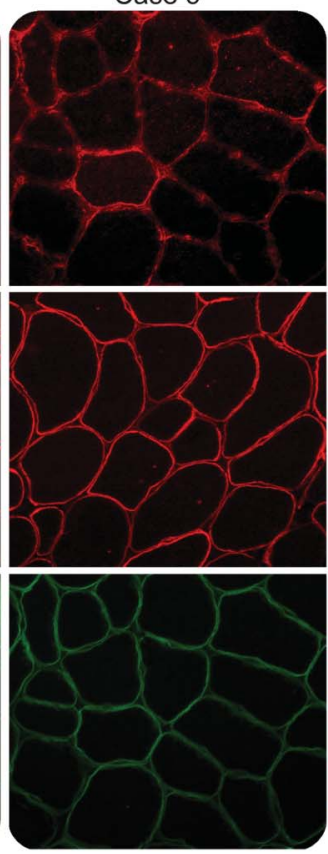

$e^{3} \times x_{0} e^{x} \times e_{0} e_{0}$

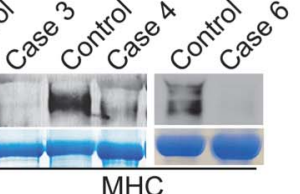

Control

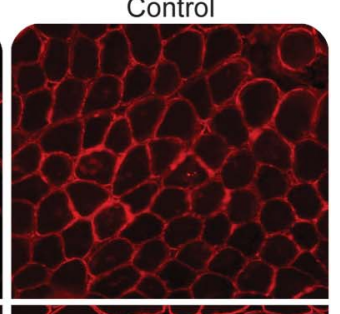

(A) T1-weighted, cross-sectional magnetic resonance images of muscles in cases 1-4. Images were acquired at C6 and L4 of the spine, at the middle of the thighs, and at the thickest part of the calves. (B) Expression of muscle proteins on Western blotting and immunofluorescence in patients with LGMD2T. Two patients express normal levels of GMPPB protein. Same analysis was not available for the rest of the participants. Expression of $\alpha$-dystroglycan ( $\alpha-D G$ ) is reduced in all patients. (C) Merosin (clone 22B2) expression appeared near normal on immunofluorescence-stained muscle sections. IIH6C-specific glycosylation of $\alpha$-DG is significantly reduced in patients, while VIA4-specific glycosylation appears normal. Bar is $50 \mu \mathrm{m}$. $\mathrm{MHC}=$ major histocompatibility complex.

Mutations in $G M P P B$ in the Danish participants were confirmed by whole-exome sequencing on DNA samples at the Broad Institute's Genomics Platform, using Illumina exome capture, 38-Mb baited target, and the Broad's in-solution hybrid selection process, and confirmed by Sanger sequencing. Sanger sequencing with bidirectional sequencing of amplicons using a Big Dye terminator was used in the French participants. 
Figure 2 Muscle involvement and muscle strength evaluation

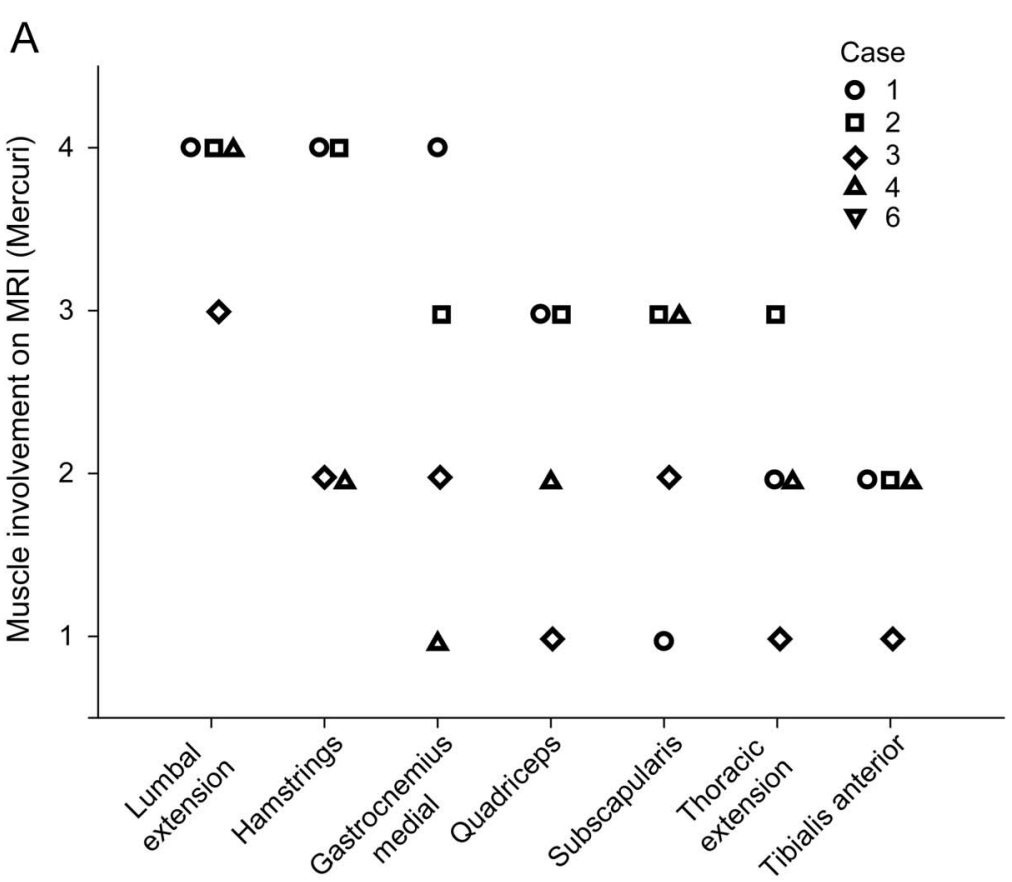

B

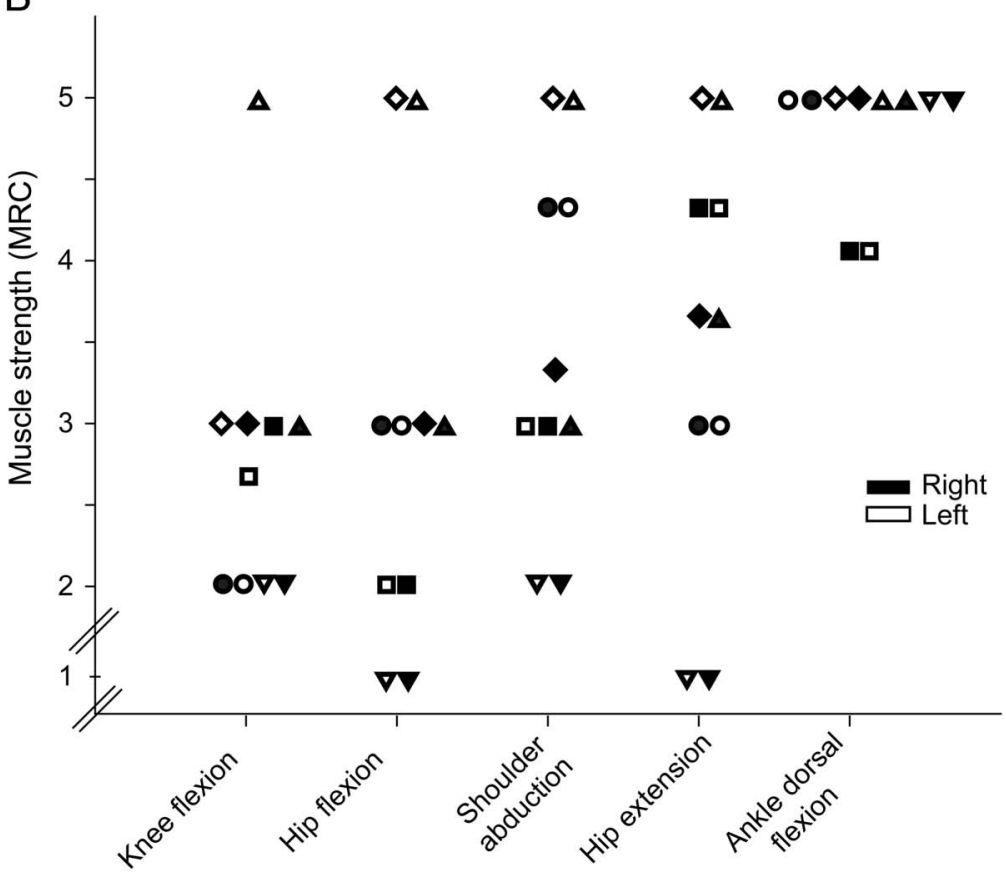

(A) Levels of muscle involvement evaluated by T1-weighted MRI using the Mercuri scale.7 (B) Muscle strength evaluation using the Medical Research Council (MRC) scale. Values 0-5, including plus and minus for 4 and 5 (4+ equals 4.33 and 5 - equals 4.66 ).

RESULTS Clinical characteristics. Onset of disease varied from 5 to 30 years of age (table). All participants presented with first symptoms related to difficulties in running and climbing stairs. Two women (cases 3 and 4) complained of fatigability and worsening of motor deficit after exercise. Five were ambulatory, but 3 of them used wheelchair outside. Strength testing showed hamstrings and hip flexor muscles to be most affected, with some asymmetry (figure 2). Four had hypertrophy of calves. None had symptoms from eyes or dysphagia, and only one had mildly affected left ventricular ejection fraction on echo.

MRI. Brain MRI was normal in all participants. The lumbar erector spinae muscle was the most severely involved muscle in all participants (figures 1 and 2). The second most affected muscles were hamstrings, which were more involved than anterior thigh muscles in all patients. We found an age-dependent gradient of muscle involvement, but no correlation between disease duration and level of muscle involvement.

Muscle biopsy. All muscle biopsies showed dystrophic changes with ring fibers, increased fibrosis, necrosis, and multiple regenerating fibers. Surprisingly, GMPPB protein was not downregulated on Western blotting (figure 1) from 2 participants, while merosin was absent (data not shown).

Immunohistology demonstrated that glycosylation of $\alpha$-dystroglycan was reduced to a spotty presence in myofibers using the IIH6C antibody, but not with the VIA4 antibody, except for 1 case (figures 1 and e-1 at Neurology.org/ng), while merosin expression appeared near normal.

Molecular findings. The mutations in GMPPB found in 4 of the participants have previously been described as pathogenic variants. ${ }^{4-6}$ One participant (case 3) was compound heterozygous for 2 new variants in $G M P P B$, and case 6 had 1 new mutation not present in the databases, such as Exome Variant Server and 1000 Genomes Project. The c.1039_1043dup (p.Ile349Serfs*) mutation is inherently pathogenic due to a frameshift, and the mutations, c.464G $>$ A (p.Arg155His) and c.902C $>$ G (p.Ser301Cys), affect highly conserved sites and are predicted to be pathogenic by 3 databases (Single Nucleotide Polymorphism/GO, SIFT, and PANTHER). The prevalence of LGMD2T in the Danish cohort was estimated to be $1.5 \%$. Creatine kinase (CK) level was elevated in all patients (table).

Neurophysiology. EMG showed a myopathic pattern mostly in proximal muscles, and repetitive stimulation disclosed a decremental response primarily in the proximal muscles at $3-\mathrm{Hz}$ stimulation of the radial, peroneral, and spinal nerves with recordings from the anconeus, tibialis anterior, and trapezius muscles (11\%-29\%). However, treatment with acetylcholine esterase inhibitors had only substantial effect in one of the 3 participants (case 3) in whom this was tested. In this latter patient, the decrement also decreased on repetitive stimulation. 
DISCUSSION The principal new findings of this study are (1) the consistent finding of a preferential affection of paraspinal and hamstring muscles in LGMD2T, (2) 3 new mutations in GMPPB, (3) variable loss of glycosylation tested with IIH6 and VIA4 antibodies, and (4) a prevalence of LGMD2T of $1.5 \%$ in Denmark. Muscle MRI and pattern of weakness have not been investigated in the approximately 14 other known ambulatory patients with LGMD2T reported so far. The pattern of preferential affection of lumbar erectors and hamstrings resembles the pattern observed in LGMD2A and is supported by findings reported in one other patient with LGMD2T. ${ }^{6}$ Calf hypertrophy in 4 of the participants is in agreement with previous findings in LGMD2T. ${ }^{4}$ The muscle involvement evaluated on MRI was not correlated with the duration of disease (table). This may be due to the patients' different understandings of disease onset as this was self-reported.

Approximately $90 \%$ of patients with LGMD followed at the Copenhagen Neuromuscular Center have a molecularly defined diagnosis. The remaining undiagnosed $10 \%$ of cases were tested for aberrations in GMPPB. Thus, in a genetically well-characterized group of 201 LGMDs, LGMD2T constitutes 1.5\%. Future studies must show whether there are geographic differences in frequency of this disorder.

We found that the level of GMPPB protein was the same in patients and healthy controls. This can be attributed to the allele carrying the c.79G $>\mathrm{C}$ mutation because the c.859C $>\mathrm{T}$ mutation has been shown to yield no protein, whereas the c.79G $>\mathrm{C}$ does. ${ }^{6}$ Patients had decreased $\alpha$-dystroglycan glycosylation. This presumably affects the binding of $\alpha$-dystroglycan to merosin, explaining the loss of merosin seen on Western blots, and thus linkage to the extracellular matrix. Presumably because of differences in sensitivity between Western blotting and immunofluorescence, merosin appeared near normal and uniformly distributed, not mosaic as seen in the VIA4 and IIH6C stains. Three of the participants, carrying the same mutations, had reduced $\alpha$-dystroglycan glycosylation assessed with the IIH6C antibody, but not VIA4, but another case with different mutations had reduced glycosylation with the VIA4 antibody (figure e-1). Patients with LGMD2I and 2M always show reduced glycosylation of $\alpha$-dystroglycan with the VIA4 antibody. 910 This demonstrates that both the VIA4 and IIH6C antibodies, commonly used for the diagnosis of dystroglycanopathies, are required for diagnosing patients suspected to have $\alpha$-dystroglycan glycosylation defects.

It has been suggested that the c.79G $>\mathrm{C}$ mutation leads to a mild phenotype of LGMD2 $\mathrm{T}^{5}$ and the c.859C $>\mathrm{T}$ to a severe one. ${ }^{6}$ Three cases were compound heterozygous for these 2 mutations in GMPPB, and MRI from these patients showed severe muscle involvement in comparison with case 4, who carried 2 mutations associated with the mild MRI involvement, thus indicating a genotype/phenotype relationship. This fits the pattern seen in the present 17 known $\alpha$-dystroglycanopathies, where phenotype/genotype relationships are generally recognized.

In accordance with previous findings in LGMD2T, ${ }^{6}$ repetitive EMG stimulation elicited a decrement of the muscle action potential, while attempts to treat the abnormality of neurotransmission have been sluggish at best. In line with this, only one patient had improved endurance on treatment with pyridostigmine. These findings suggest abnormalities of the neuromuscular junction related to abnormal glycosylation, which cannot be completely corrected by conventional antimyasthenic treatment. Thus, in a context of LGMD with high CK levels, a decremental response may be an important diagnostic clue toward genetic analysis of GMPPB.

\section{AUTHOR CONTRIBUTIONS}

S.T. Oestergaard: design of study, analysis, acquisition and interpretation of data, and drafting the manuscript. T. Stojkovic: acquisition of data and revision of manuscript. J.R. Dahlqvist: design of study, analysis, acquisition and interpretation of data, and drafting the manuscript. C. Bouchet-Seraphin, J. Nectoux, F. Leturcq, M. Cossée, G. Solé, and C. Thomsen: acquisition of data and revision of manuscript. T.O. Krag: acquisition and interpretation of data and revision of manuscript. J. Vissing: design of study, acquisition and interpretation of data, and revision of manuscript.

\section{ACKNOWLEDGMENT}

The authors thank Dr. Norma Beatriz Romero, Dr. Pascale Marcorelles, and Emmanuelle Lacéne for providing immunohistochemistry pictures from the French participants. They also thank Dr. Fanny Duval from the center of reference for neuromuscular disorders, CHU Bordeaux, France, for the opportunity to include an additional participant to the article.

\section{STUDY FUNDING}

No targeted funding reported.

\section{DISCLOSURE}

S.T. Oestergaard has received travel funding from the Lundbeck Foundation. Dr. Stojkovic has received speaker honoraria from the Laboratory LFB (Laboratoire français du fractionnement et des biotechnologies). Dr. Dahlqvist, Dr. Bouchet-Seraphin, Dr. Nectoux, Dr. Leturcq, and Dr. Cossée report no disclosures. Dr. Solé has served on the scientific advisory board of CSL Behring; has received travel funding from Laboratoire Français de biotechnologie, CSL Behring, and Sanofi Genzyme; and has received research support from CSL Behring and AFM-Téléthon. Dr. Thomsen holds a patent for Optical motion tracking of an object (WO 2011/113441 A2). Dr. Krag has received research support from the AP Møller Foundation and Augustinus Foundation. Dr. Vissing has served on the scientific advisory board of Genzyme; has received travel and speaker honoraria from Genzyme; has served on the editorial board of Neuromuscular Disorders and the Journal of Neuromuscular Diseases; has been a consultant for NOVO Nordic Industries (Denmark); and has received research support from the Lundbeck Foundation, the NOVO Foundation, the Danish Medical Research Council, University of Copenhagen, and the research Committee of the National Hospital. Go to Neurology.org/ng for full disclosure forms.

Received June 29, 2016. Accepted in final form September 8, 2016. 


\section{REFERENCES}

1. Nigro V, Savarese M. Genetic basis of limb-girdle muscular dystrophies: the 2014 update. Acta Myol 2014;33:1-12.

2. Carss KJ, Stevens E, Foley AR, et al. Mutations in GDPmannose pyrophosphorylase B cause congenital and limbgirdle muscular dystrophies associated with hypoglycosylation of $\alpha$-dystroglycan. Am J Hum Genet 2013;93:29-41.

3. Adams JC, Brancaccio A. The evolution of the dystroglycan complex, a major mediator of muscle integrity. Biol Open 2015;4:1163-1179.

4. Cabrera-Serrano M, Ghaoui R, Ravenscroft G, et al. Expanding the phenotype of GMPPB mutations. Brain 2015;138: 836-844.

5. Jensen BS, Willer T, Saade DN, et al. GMPPB-associated dystroglycanopathy: emerging common variants with phenotype correlation. Hum Mutat 2015;36:1159-1163.

6. Belaya K, Rodríguez Cruz PM, Liu WW, et al. Mutations in GMPPB cause congenital myasthenic syndrome and bridge myasthenic disorders with dystroglycanopathies. Brain 2015;138:2493-2504.

7. Mercuri E, Talim B, Moghadaszadeh B, et al. Clinical and imaging findings in six cases of congenital muscular dystrophy with rigid spine syndrome linked to chromosome 1p (RSMD1). Neuromuscul Disord 2002;12: 631-638

8. Krag TO, Vissing J. A new mouse model of limb-girdle muscular dystrophy type 2I homozygous for the common L276I mutation mimicking the mild phenotype in humans. J Neuropathol Exp Neurol 2015;74:1137-1146.

9. Krag TO, Hauerslev S, Sveen ML, et al. Level of muscle regeneration in limb-girdle muscular dystrophy type 2I relates to genotype and clinical severity. Skelet Muscle 2011;1:31.

10. Riisager M, Duno M, Hansen FJ, et al. A new mutation of the fukutin gene causing late-onset limb girdle muscular dystrophy. Neuromuscul Disord 2013;23:562-567. 


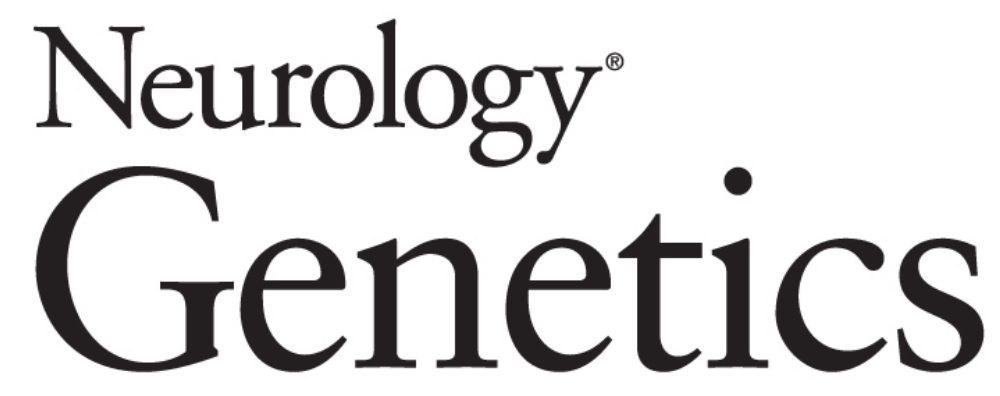

\section{Muscle involvement in limb-girdle muscular dystrophy with GMPPB deficiency (LGMD2T)}

S.T. Oestergaard, T. Stojkovic, J.R. Dahlqvist, et al. Neurol Genet 2016;2;

DOI 10.1212/NXG.0000000000000112

This information is current as of October 11, 2016

\section{Updated Information \& Services}

Supplementary Material

References

Citations

Subspecialty Collections

Permissions \& Licensing

Reprints including high resolution figures, can be found at: http://ng.neurology.org/content/2/6/e112.full.html

Supplementary material can be found at: http://ng.neurology.org/content/suppl/2016/10/11/2.6.e112.DC1

This article cites 10 articles, 1 of which you can access for free at: http://ng.neurology.org/content/2/6/e112.full.html\#\#ref-list-1

This article has been cited by 3 HighWire-hosted articles: http://ng.neurology.org/content/2/6/e112.full.html\#\#otherarticles

This article, along with others on similar topics, appears in the following collection(s):

MRI

http://ng.neurology.org//cgi/collection/mri

Muscle disease

http://ng.neurology.org//cgi/collection/muscle_disease

Information about reproducing this article in parts (figures,tables) or in its entirety can be found online at:

http://ng.neurology.org/misc/about.xhtml\#permissions

Information about ordering reprints can be found online: http://ng.neurology.org/misc/addir.xhtml\#reprintsus

Neurol Genet is an official journal of the American Academy of Neurology. Published since April 2015, it is an open-access, online-only, continuous publication journal. Copyright ( 2016 American Academy of Neurology. All rights reserved. Online ISSN: 2376-7839.

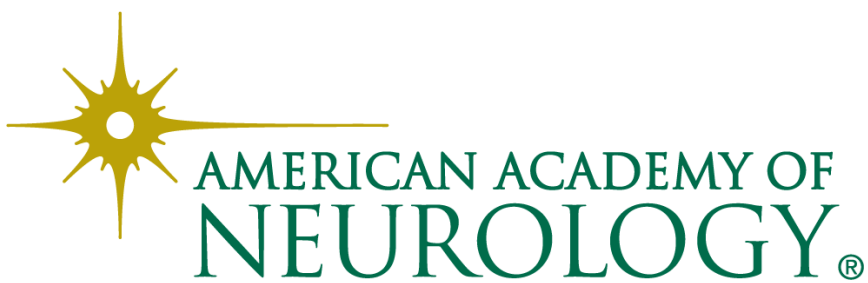

